\title{
Reuse of volcanic mud to controlled low-strength materials with cement and alkali-activated slag binders
}

\author{
Chung-Ho Huang ${ }^{*}$ and Hao-Yu Fang \\ Department of Civil Engineering, National Taipei University of Technology, No.1, Sec. 3, Zhongxiao E. Rd., Da'an Dist., Taipei City \\ 106, Taiwan
}

\begin{abstract}
This paper aims to evaluate the applicability of volcanic mud as the fine aggregate for controlled low-strength material (CLSM) by the experimental method. Two types of binder were selected, including cement and alkali-activated slag binders (without cement). The study mainly explored the effects of different addition rates of volcanic mud and different concentrations of alkaline agents (sodium hydroxide) on the engineering properties of CLSM. The test results show that the CLSMs with cement and volcanic mud have better workability and less water bleeding. However, the compressive strength of CLSM decreases as the replacement rate of volcanic mud increases, and the setting time also increases. The replacement rate of volcanic mud is recommended to be $20 \%$. The volcanic mud mixed with the alkaliactivated slag binder (without cement) can be successfully made into CLSM. When the concentration of sodium oxide in CLSM is 5\%, although the compressive strength is highest at 7 days or 28 days, it cannot be hardened at the early age (before four days) and without compressive strength. CLSM with $20 \%$ sodium oxide concentration has poor workability. Its compressive strength is slightly lower than that of the $10 \%$ group. Therefore, the amount of calcium hydroxide recommended is $10 \%$.
\end{abstract}

\section{Introduction}

Mud volcanoes are mainly distributed in southwestern Taiwan, and a large amount of volcanic mud is emitted from time to time every year. It is often covered in farmland, causing crop losses and sometimes causing damage to public facilities. When the volcanic mud is dried, it forms a hard clod, which makes it difficult to clean up. Common treatments for cleared volcanic mud include landfill and ocean dumping [1-2]. Ocean dumping was banned due to restrictions on the United Nations Convention on the Law of the Sea. Therefore, volcanic mud is mainly used as waste and is mainly treated by landfill. For volcanic mud erupted in farmland, farmers can only use the disaster relief fund to carry out waste cleaning, and it is urgent to find new treatment methods to achieve the concept and requirements of environmental protection. In summary, the treatment of volcanic mud as waste has conflicted with the concept of environmental protection. How to effectively reuse volcanic mud is an important research topic.

The volcanic mud is slurry that is retained by the formation water of the mud volcano and dissolved in the mudstone after being ejected by water and gas pressure. Volcanic mud is mainly composed of clay minerals (such as illite, kaolin and Montmorillonite), fine rock debris (such as quartz, feldspar and mica), epigenetic minerals (such as chlorite and green window stone), solubility, and organic matters. The volcanic mud particles are less than $45 \mu \mathrm{m}$ in particle size and do not meet the specifications for concrete aggregates [3]. It is not the case that fly ash and slag powder can react with binder products. Therefore, volcanic mud is not suitable for use as the aggregate or admixture in concrete materials.

Controlled Low Strength Materials (CLSMs) possess high workability and low strength. It can also be called fluid filling material, non-shrinking filling material and fluid mortar due to its self-flowing and self-filling properties. CLSMs are mainly composed of cement, water, coarse aggregates, and fine aggregates, mainly composed of fine-grained materials, sometimes mixed with pozzolanic materials, such as fly ash, slag, and rice husk ash. Its structure is loose and low in strength. Unlike ordinary concrete materials, it requires dense and high strength. In application, CLSM is mainly used in construction sites where small spaces or machines cannot enter, instead of traditional backfilled tamping materials. For foundation fills or other permanent works of buildings, the compressive strength should be lower than $83 \mathrm{kgf} / \mathrm{cm}^{2}$ (8.3 MPa). When CLSM is applied to the reexcavation project, its compressive strength must be between 3 and $21 \mathrm{kgf} / \mathrm{cm}^{2}(0.3 \sim 2.1 \mathrm{MPa})$, and the bearing strength must be $3 \sim 7 \mathrm{kgf} / \mathrm{cm}^{2}(0.3 \sim 0.7 \mathrm{MPa})$ [4]. The 28day design strength of the CLSM is usually limited to 20 to $90 \mathrm{kgf} / \mathrm{cm}^{2}$. A number of scholars have studied the use of different wastes in CLSM [5-8], such as oyster shells, purified water sludge, cement kiln dust and slag, fly ash, blast furnace slag, and bottom ash. However, different types of waste have different characteristics, and possible addition methods or application techniques will have an

\footnotetext{
* Corresponding author: cdewsx.hch@gmail.com
} 
impact on the properties of CLSM. This study intends to conduct experimental research on the application of volcanic mud to CLSM.

\section{Research project}

In this study, CLSM was prepared by replacing fine aggregates with volcanic mud and adding different concentrations of alkali activators for fresh and hardened properties. In this study, CLSM was prepared by replacing fine aggregate with volcanic mud and adding different concentrations of alkali activator for fresh and hard solid properties. Test materials, test methods, test variables, and mixture design are as follows.

This study used civil engineering materials in accordance with ASTM specifications, including type I Portland cement, slag powder with a fineness of 6000 , class F fly ash, coarse and fine aggregates, and tap water. The volcanic mud is taken from Wandan Township, Pingtung County, Taiwan, with a specific gravity of 2.69. The main component is clay mineral, and the average particle size D50 is about $0.0137 \mathrm{~mm}$. In order to measure the fresh and hardened properties of CLSM, the test items included flow consistency, unit weight, bleeding, setting time, and compressive strength test. The test methods are all tested according to the American ASTM related specifications.

The experimental variables in this study are divided into two parts. The first part mainly studies the engineering properties of volcanic mud instead of finegrained CLSM. The second part discusses the engineering properties of different concentrations of alkali-agents added to CLSM. In order to explore the influence of volcanic mud on CLSM, volcanic mud replaced fine granules with different proportions, and CLSM was mixed with two water-to-binder ratios to explore the effects of different volcanic mud substitution rates and different water-to-binder ratios on engineering properties. The test variables have a water-to-gel ratio of 0.83 and 1.15, respectively, and the volcanic mud replaces the fine particle rate by $10 \%, 20 \%, 30 \%, 50 \%$, $75 \%, 100 \%$, and the three alkali excitation concentrations. The Mixture design results are shown in Table 1.

Table 1. Mixture of CLSMs $\left(\mathrm{kg} / \mathrm{m}^{3}\right)$.

\begin{tabular}{|c|c|c|c|c|c|c|c|c|}
\hline No. & VM & S & CA & FA & SL & C & W & N \\
\hline C10M00N00 & 0 & 1270 & 400 & 25 & 25 & 250 & 250 & 0 \\
\hline C10M10N00 & 129 & 1143 & 400 & 25 & 25 & 250 & 301 & 0 \\
\hline C10M20N00 & 258 & 1016 & 400 & 25 & 25 & 250 & 353 & 0 \\
\hline C10M30N00 & 388 & 889 & 400 & 25 & 25 & 250 & 405 & 0 \\
\hline C10M50N00 & 646 & 635 & 400 & 25 & 25 & 250 & 508 & 0 \\
\hline C10M75N00 & 970 & 317 & 400 & 25 & 25 & 250 & 612 & 0 \\
\hline C10M100N00 & 1293 & 0 & 400 & 25 & 25 & 250 & 638 & 0 \\
\hline C15M00N00 & 0 & 1340 & 400 & 25 & 25 & 166 & 250 & 0 \\
\hline C15M10N00 & 136 & 1206 & 400 & 25 & 25 & 166 & 304 & 0 \\
\hline C15M20N00 & 272 & 1072 & 400 & 25 & 25 & 166 & 359 & 0 \\
\hline C15M30N00 & 409 & 938 & 400 & 25 & 25 & 166 & 413 & 0 \\
\hline C15M50N00 & 682 & 670 & 400 & 25 & 25 & 166 & 522 & 0 \\
\hline C15M75N00 & 1023 & 335 & 400 & 25 & 25 & 166 & 659 & 0 \\
\hline C15M100N00 & 1364 & 0 & 400 & 25 & 25 & 166 & 795 & 0 \\
\hline C15M50S100N05 & 688 & 676 & 400 & 0 & 166 & 0 & 526 & 13 \\
\hline C15M50S100N10 & 675 & 663 & 400 & 0 & 166 & 0 & 525 & 25 \\
\hline
\end{tabular}

\begin{tabular}{|l|l|l|l|l|l|l|l|l|}
\hline C15M50S100N20 & 650 & 639 & 400 & 0 & 166 & 0 & 520 & 50 \\
\hline
\end{tabular} $\mathrm{VM}=$ volcanic mud; $\mathrm{S}=$ Sand; $\mathrm{CA}=$ Coarse Aggregate; $\mathrm{FA}=$ Fly ash; $\mathrm{SL}=$ Slag; $\mathrm{C}=$ Cement; $\mathrm{W}=$ Water; $\mathrm{N}=\mathrm{NaOH}$

\section{Test results and discussion}

\subsection{Atterberg Limit tests for volcanic mud}

In this study, volcanic mud was considered as smallgrained soil, and soil Index Properties were determined under different water contents. The results of Atterberg Limit tests are shown in Table 2. From the analysis of the test results, it can be inferred that the Liquid Limit of the volcanic mud is about $22 \%$, which means that the minimum flowable water content of the volcanic mud is about $22 \%$. The test results of tube flow of volcanic mud are shown in Table 3 . The average tube flow of volcanic mud mixed with $30 \%$ water is $100 \mathrm{~mm}$, the average tube flow of $35 \%$ water mixing is $150 \mathrm{~mm}$, and the mean tube flow of $40 \%$ water mixing is about $182 \mathrm{~mm}$. According to the test results, in order to consider the workability of CLSM, it is recommended that the dry volcanic mud should add $40 \%$ of water, which can make the CLSM have certain workability.

Table 2. Test results of Atterberg limit test.

\begin{tabular}{|c|c|c|c|c|c|c|c|}
\hline No & $\mathrm{A}(\mathrm{N})$ & $\mathrm{B}(\mathrm{g})$ & $\mathrm{C}(\mathrm{g})$ & $\mathrm{D}(\mathrm{g})$ & $\mathrm{E}(\mathrm{g})$ & $\mathrm{F}(\mathrm{g})$ & $\mathrm{Y}(\%)$ \\
\hline 1 & 13 & 19.163 & 15.664 & 1.409 & 14.255 & 3.499 & 24.546 \\
\hline 4 & 15 & 21.180 & 17.394 & 1.411 & 15.983 & 3.786 & 23.688 \\
\hline 2 & 17 & 16.967 & 13.998 & 1.405 & 12.593 & 2.969 & 23.577 \\
\hline 3 & 18 & 21.482 & 17.715 & 1.407 & 16.308 & 3.767 & 23.099 \\
\hline 5 & 21 & 20.770 & 17.210 & 1.414 & 15.796 & 3.560 & 22.537 \\
\hline \multicolumn{8}{|c|}{$\mathrm{Y}=-4.05 \ln (\mathrm{N})+34.764 \quad \mathrm{~N}=25, \mathrm{Y}=22 \%$} \\
\hline
\end{tabular}

Table 3. Test results of tube flow of volcanic mud pastes.

\begin{tabular}{|c|c|c|c|}
\hline \multirow{2}{*}{ No. } & \multicolumn{3}{|c|}{ Added water } \\
\cline { 2 - 4 } & $30 \%$ & $35 \%$ & $40 \%$ \\
\hline C15M10N00 & $100 \times 100(100)$ & $140 \times 140(140)$ & $160 \times 170(165)$ \\
\hline C15M20N00 & $100 \times 100(100)$ & $165 \times 165(165)$ & $190 \times 200(195)$ \\
\hline C15M30N00 & $100 \times 100(100)$ & $140 \times 150(145)$ & $180 \times 190(185)$ \\
\hline
\end{tabular}

\subsection{Fresh properties of CLSM}

\subsubsection{Workability}

In this study, the workability of volcanic mud CLSM was determined by tube flow and slump test. The experimental results are compared and analyzed in Figure 1. When volcanic mud replaces fine aggregates added to CLSM and the substitution rate is less than $20 \%$, the amount of volcanic mud increases, which can increase the tube flow and slump values of CLSM by about $40 \%$. The effect of sodium hydroxide solution concentration on the workability of CLSM is shown in Figure 2. It can be seen from the figure that the concentration of sodium hydroxide solution is increased from $5 \%$ to $10 \%$, and the slump flow value of CLSM is reduced by about $1.8 \%$. When the concentration of sodium hydroxide solution 
was increased to $20 \%$, the slump flow value of CLSM was reduced by about $23.1 \%$. It shows that the concentration of sodium hydroxide alkali agent added by CLSM is less than $10 \%$, which has little effect on the workability. However, when the concentration reaches $20 \%$, the slump flow of CLSM will be greatly reduced, and the amplitude can reach $23 \%$.

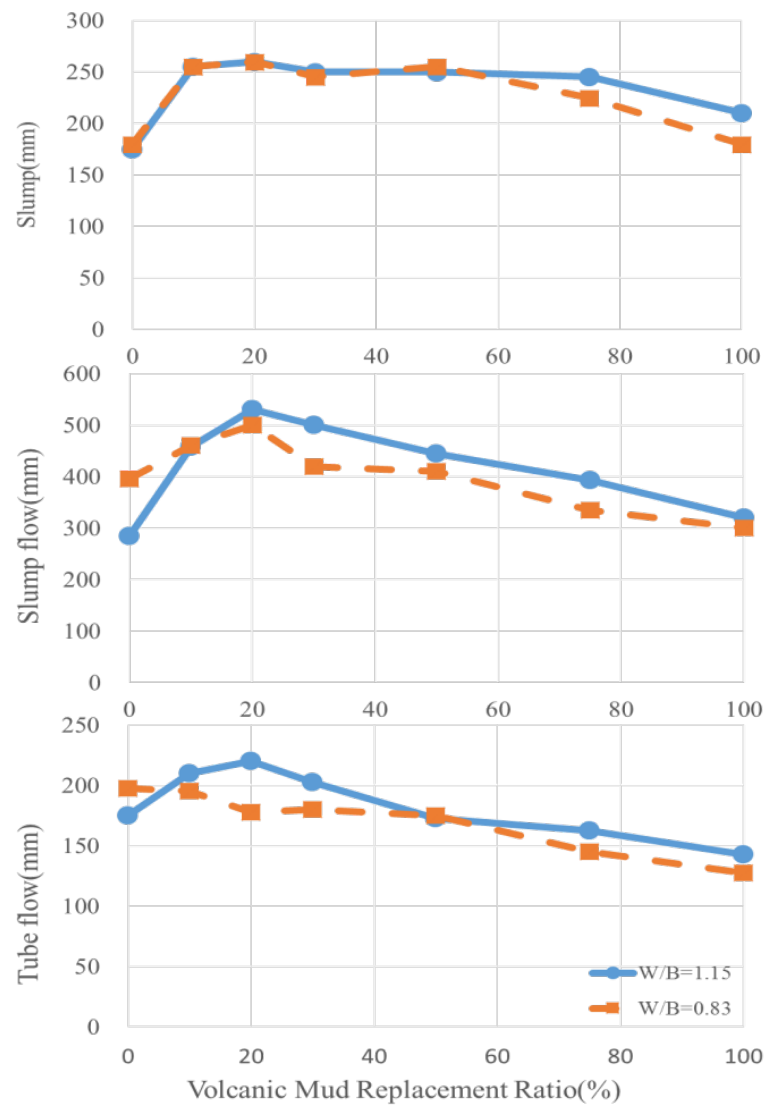

Fig. 1. Relationship between the replacement ratio of volcanic mud and the workability of CLSM.

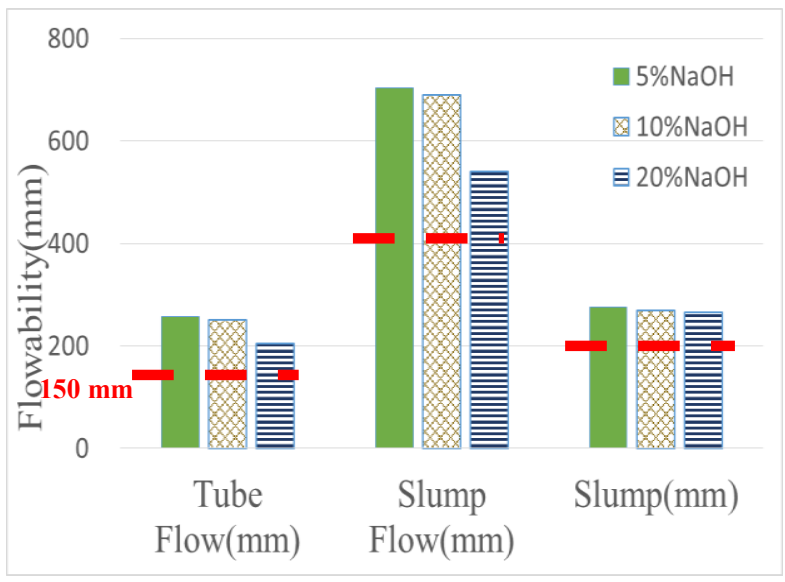

Fig. 2. Effect of sodium hydroxide concentration on the workability of the CLSMs.

\subsubsection{Bleeding test}

The results of the bleeding test of the volcanic mud CLSM are shown in Table 4 . The test results show that the bleeding water rate of CLSM without volcanic mud is about $2.5 \%$. When the volcanic mud is incorporated into the CLSM, the bleeding rate is less than $1 \%$, and almost no bleeding occurs. Adding sodium hydroxide solution to the CLSM will increase the temperature of the test sample and accelerate the chemical reaction, so that the CLSMs have almost no bleeding. Therefore, the addition of volcanic mud or sodium hydroxide alkali to CLSM will inhibit the occurrence of bleeding.

Table 4. Bleeding and setting time of CLSMs.

\begin{tabular}{|c|c|c|c|}
\hline \multirow{2}{*}{ No. } & \multirow{2}{*}{$\begin{array}{c}\text { Bleeding } \\
(\%)\end{array}$} & $\begin{array}{c}\text { Setting time } \\
\text { (nitial set } \\
\text { (hr:min) }\end{array}$ & $\begin{array}{c}\text { Final set } \\
\text { (hr:min) }\end{array}$ \\
\hline C10M00N00 & $2.50 \%$ & $08: 52$ & $17: 42$ \\
\hline C10M10N00 & $0.96 \%$ & $07: 59$ & $12: 10$ \\
\hline C10M20N00 & $0.60 \%$ & $09: 14$ & $18: 07$ \\
\hline C10M30N00 & $0.61 \%$ & $09: 35$ & $19: 47$ \\
\hline C10M50N00 & $0.60 \%$ & $12: 57$ & $31: 12$ \\
\hline C10M75N00 & $0.00 \%$ & $15: 33$ & $37: 06$ \\
\hline C10M100N00 & $0.00 \%$ & $21: 15$ & $41: 38$ \\
\hline C15M00N00 & $2.10 \%$ & $07: 31$ & $13: 21$ \\
\hline C15M10N00 & $1.25 \%$ & $09: 57$ & $21: 08$ \\
\hline C15M20N00 & $1.19 \%$ & $10: 11$ & $24: 37$ \\
\hline C15M30N00 & $0.61 \%$ & $15: 14$ & $29: 41$ \\
\hline C15M50N00 & $0.61 \%$ & $19: 30$ & $33: 56$ \\
\hline C15M75N00 & $0.12 \%$ & $36: 22$ & $71: 01$ \\
\hline C15M100N00 & $0.00 \%$ & $49: 36$ & $92: 55$ \\
\hline C15M50S100N05 & $0.02 \%$ & $55: 26$ & $90: 05$ \\
\hline C15M50S100N10 & $0.00 \%$ & $04: 32$ & $58: 46$ \\
\hline C15M50S100N20 & $0.00 \%$ & $02: 00$ & $41: 16$ \\
\hline
\end{tabular}

\subsubsection{Setting time}

The setting time test results of CLSM are shown in Table 4. The test results show that the volcanic mud completely replaces the fine aggregate, and the initial setting time of $0.83 \mathrm{~W} / \mathrm{B}$ CLSM is extended by about 12 hours, and the final setting time is extended by about 24 hours. 1.15 W/B CLSM will increase the initial setting time by about 42 hours, and the final setting time will increase by about 79 hours. When the concentration of the sodium hydroxide solution was $5 \%$, the initial setting time was about 55 hours, and the final setting time was 90 hours. When the concentration of the sodium hydroxide solution was increased to $10 \%$, the initial setting time was reduced by about 51 hours, which was about $91 \%$ faster. The final setting time is also reduced by nearly $50 \%$. The setting time is greatly shortened as the concentration of the sodium hydroxide solution increases. Therefore, the addition of sodium hydroxide to the CLSM can increase the temperature of the test body, accelerate the chemical reaction rate, and produce a regulated-set effect. And the higher the concentration of sodium hydroxide solution, the more obvious the effect of regulated-set is.

\subsection{Compressive Strength of CLSMs}

The compressive strength development curves of CLSM with low and high water-binder ratios $(0.83$ and 1.15$)$ are shown in Figures 3 and Figure 4, respectively. The compressive strength of all CLSMs increases with age, 
but CLSMs with different volcanic mud content have different compressive strength growth rates. When the CLSM is at a water-to-binder ratio of 0.83 (as shown in Figure 3), the strength growth rate from 7 days to 28 days is $2.62 \mathrm{kgf} / \mathrm{cm}^{2} /$ day in the control group, As the volcanic mud replacement rates are at $10 \%, 20 \%, 30 \% .50 \%, 75 \%$, $100 \%$, the strength growth rates were $2.61,1.63,1.15$, $0.85,0.44,0.28 \mathrm{kgf} / \mathrm{cm}^{2} /$ day, respectively. When the CLSM is at the 1.15 water-to-binder ratio(as shown in Figure 4), the volcanic mud replacement rate is higher than $50 \%$, and the compressive strength growth rate from 7 days to 28 days is less than $0.50 \mathrm{kgf} / \mathrm{cm}^{2} /$ day. Regardless of the water-to-binder ratio, volcanic mud replaces fine aggregates added to CLSM, and the replacement rate is higher than $30 \%$ by weight, which will greatly delay the compressive strength growth of CLSM.

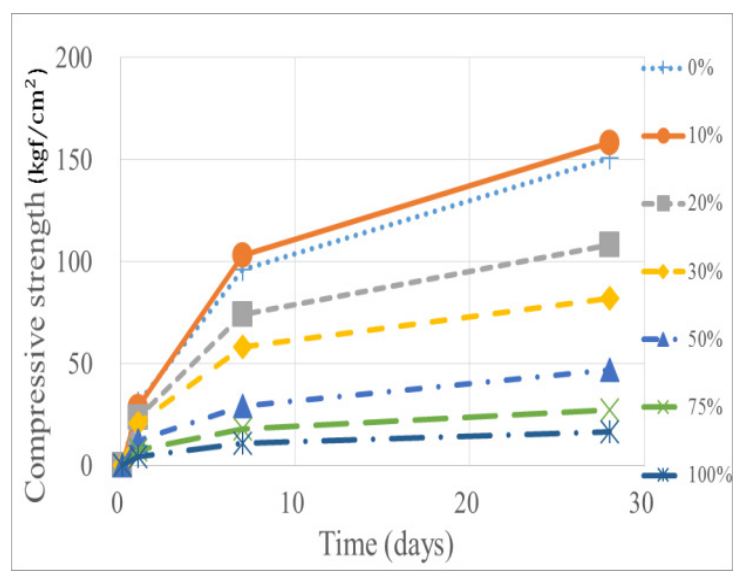

Fig. 3. Compressive strength development of CLSM with volcanic mud $(\mathrm{W} / \mathrm{B}=0.83)$.

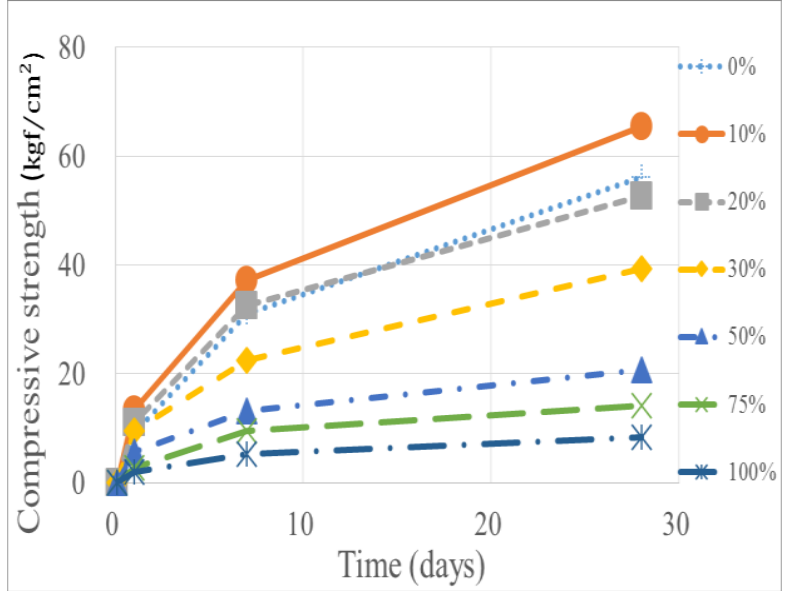

Fig. 4. Compressive strength development of CLSM with volcanic mud $(\mathrm{W} / \mathrm{B}=1.15)$.

Figure 5 shows the effect of volcanic mud replacement rate on the 28-day compressive strength of CLSM. The volcanic mud replacement rate was $10 \%$, and the compressive strengths of the CLSM with two waterto-binder ratios increased by $5 \%$ and $17 \%$, respectively, compared with the control group $(0 \%)$. Adding a small amount of volcanic mud is beneficial to the compressive strength properties of CLSM. The reason for the estimation may be that the volcanic mud particles are finer and can function to fill the pores, so that the density and strength of the CLSM specimens are higher. However, when the volcanic mud replacement rate is higher than $30 \%$, the compressive strength of CLSM is reduced by about $30 \%$ to $50 \%$ compared with the control group. When the volcanic mud completely replaces the fine aggregate (100\% replacement rate), the compressive strength of CLSM is reduced by about $80 \%$ to $90 \%$. The higher the replacement rate of volcanic mud is, the lower the compressive strength of CLSM is. The main reason is that when a large amount of volcanic mud is replaced, it is necessary to add a large amount of water to maintain the workability, so that the strength of the CLSM is greatly reduced.

The strength growth of CLSM with different sodium hydroxide concentrations is shown in Fig. 6. When the concentration of sodium hydroxide solution is less than $5 \%$, the compressive strength of CLSM with alkaliactivated slag binders cannot be measured at 1 day of age. It can be found that calcium hydroxide is used as an alkali agent the concentration is too low to activate slag to produce hydration. After three days, the alkaliactivated reaction slowly increases the compressive strength of CLSM with 5\% sodium oxide solution and slag reached 24 and $29 \mathrm{kgf} / \mathrm{cm}^{2}$ at 7 days and 28 days, respectively, which were higher than those of CLSM with $10 \%$ and $20 \%$ sodium hydroxide solution. The main reason is that the higher the concentration, the faster the chemical reaction and the higher strength development. When the concentration of sodium hydroxide solution is higher than $5 \%$, the initial reaction is too intense, which makes the sample easy to have micro-cracks and material packing is not dense enough. This resulted in a decrease in the compressive strength growth rate of 7 days and 28 days. Although the compressive strength of the $5 \%$ group is higher at 28 days, the initial strength is insufficient to limit the ease of construction of the CLSM. Therefore, it is recommended that the concentration of sodium hydroxide added by CLSM with alkali-activated slag binders be $10 \%$.

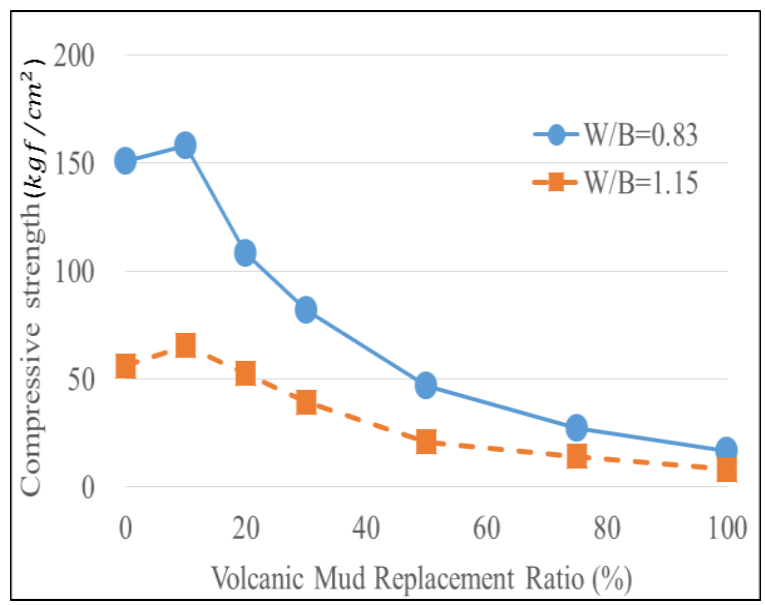

Fig. 5. Effect of replacement rate of volcanic mud on the compressive strength of CLSMs. 


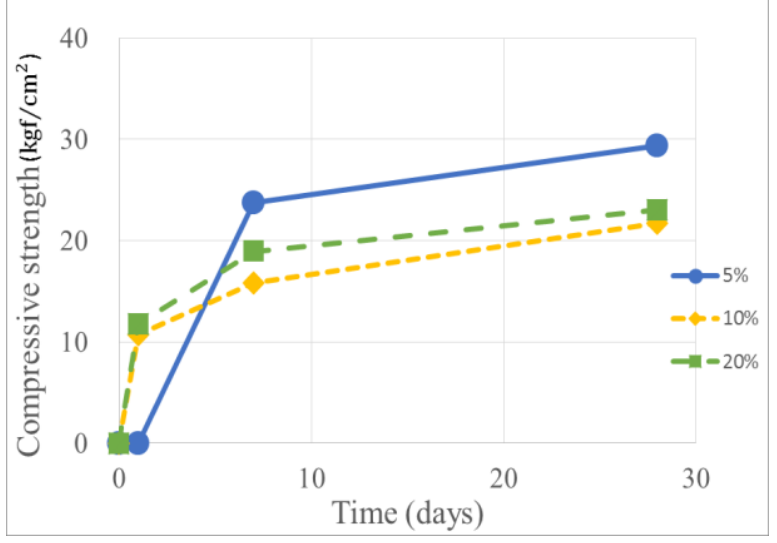

Fig. 6. Effects of sodium hydroxide concentration on the compressive strength of CLSMs.

\section{Conclusion}

Based on the tests, the following conclusion can be reached:

1. According to the results of the Atterberg Limit test and tube flow test, the dry volcanic mud powder requires an additional $40 \%$ by weight of water, and the volcanic mud CLSM can meet the construction workability.

2. When the replacement rate of volcanic mud is low (less than 20\%), it is beneficial to the workability of CLSM. When the volcanic mud replacement rate is greater than $20 \%$, the slump flow and tube flow of CLSM are reduced by about $40 \%$. The CLSM with sodium hydroxide as the alkaline agent has less influence on the workability of the CLSM when the concentration of the sodium hydroxide solution is less than $10 \%$. However, when the concentration reaches $20 \%$, the workability of CLSM will be greatly reduced. The slump flow and tube flow of CLSM are reduced by $23 \%$.

3. Adding volcanic mud to CLSM can effectively reduce the bleeding of CLSM. Adding a high concentration $(10 \%$ or more) of sodium hydroxide solution accelerates the hydration of slag, thereby reducing water seepage. Therefore, CLSM with alkaliactivated slag binder is also less bleeding.

4. The high water-to-binder ratio and high volcanic mud replacement rate cause a large amount of water inside the CLSM to slow down the hydration reaction. This will make the setting time of the CLSM approximately 5 times longer. With a high concentration of sodium hydroxide solution and slag powder, the setting time of CLSM is shortened by more than $50 \%$.

5. Adding a little volcanic mud (replacement rate less than $10 \%$ ) will increase the density of the CLSM sample, and its strength can be increased by about $16 \%$. Since the volcanic mud has an additional $40 \%$ water, high volcanic mud will increase the CLSM porosity and the strength will decrease.

\section{References}

1. M.P. Carignan, C.B. Lake, T. Menzies, Waste Management and Research,25(2007).

2. G.E. Otott and T.K. Mikel, Society of Petroleum Engineers of AIME, SPE-18052-MS(1988).

3. ASTM C33/C33M-13 Standard Specification, United States.

4. B. W. Ramme, ACI 229R-99(1999).

5. W.T. Kuo, Construction and Building Materials, 46, (2013).

6. X.L. Fang, L. Wang, C.S. Poona, B. Kitae, C.W. Tsang, S.K. Kwok. Journal of Environmental Management, 232 (2019).

7. M. Lachemi, M. Sahmaran, K.M.A. Hossain, A. Lotfy, M. Shehata. Cement and Concrete Composites, 32(2010).

8. N.K. Lee, H.K. Kim, I.S. Park, H.K. Lee, Construction and Building Materials, 49(2013). 